\title{
The Potential Anti Helicobacter pylori and antioxidant effects of Artemisia Judaica
}

\section{Adel El-Sayed ${ }^{1}$, Radwan BaAbbad ${ }^{2}$, Amal Balash ${ }^{3}$, Nasser A. Al-Hemdan ${ }^{4}$ and Abdullah Softah ${ }^{5}$}

\author{
${ }^{1}$ Pharmacology, ${ }^{2}$ Medical Microbiology, ${ }^{3}$ Biochemistry, ${ }^{4}$ Community Medicine departments, \\ ${ }^{5}$ Undergraduate Medical Student, Faculty of Medicine, King Saud Bin Abdulaziz University \\ for Health Sciences, KSA
}

Corresponding author: Amal Balash, PhD, Biochemistry Department, Faculty of Medicine, King Saud Bin Abdulaziz University for Health Sciences, KSA

Submission date: March 17, 2013; Acceptance date: September 19, 2013; Publication date: September 26, 2013

\begin{abstract}
Artemisia judaica $(A J)$ is one of the common species of the genus Artemisia that grows in Saudi Arabia desert and Sinai, Egypt where animals graze on it. It is widely used in traditional medicine and by Bedouins there. $(A J)$ has anthelmintic, antibacterial, antiinflammatory, analgesic and antipyretic effects. The present study aimed to (1) elucidates the antibacterial action of $A J$ against $H$. pylori and different other bacterial species (2) delineate the potential antibacterial mechanism of action of $A J$ in comparison with tetracycline and cefotaxime (3) measure the trolox equivalent antioxidant capacity (TEAC) of the AJ water extract. Preparation of the $(A J)$ extracts was done by three different methods two of them are usually performed by population in Middle East by boiling of the shade-dried herb in water as tea (decoction), or soaked in tap water for over night (infusion), other method was done by concentrating the aqueous extract of Artemisia judaica under vacuum. The results of this study revealed that $(A J)$ has neither antibacterial effects either against $\mathrm{H}$. pylori nor any other bacterial species. On the other hand the extract of AJ prepared by any of the above mentioned methods shows significant $(\mathrm{p}<0.005)$ antioxidant action as compared with blank and related to trolox antioxidant capacity.
\end{abstract}

Key words: Artemisia judaica, Helicobacter pylori, antioxidant capacity

\section{INTRODUCTION:}

Artemisia judaica $\mathrm{L}(A J)$ is a desert medicinal plant commonly used as tea by population of Saudi Arabia, and in Egypt Sinai. In the traditional medicine of the Arabic area; Artemisia judaica is used in the treatment of gastrointestinal disorders, enhanced eyesight, cardiovascular health, capillary strength, and structure of connective tissue, appearance of skin, and immune systems as well as decreased risk of atherosclerosis, cancer, and arthritis $[1,2]$. 
Artemisia judaica, belongs to the family Compositae, and is a fragrant shrub that grows widely in the Arabian area. Phytochemical analysis of A.J shows that it is a rich source of flavonoids including apigenin, cirsimaritin, and various novel compounds [3, 4, and 5].

Artemisia family extract showed significant higher antioxidant effect [6]. There are also evidences that Artemisia family can improve diabetes mellitus in addition to their antimicrobial and anti-fungal effects [7].

Free radicals generation is involved in many disorders include non-steroidal antiinflammatory drugs (NSAIDs)-induced peptic ulcers [8]. Helicobacter pylori (H. pylori) are the bacteria responsible for most ulcers and many cases of stomach inflammation (chronic gastritis). The bacteria can weaken the protective coating of the stomach, allowing digestive juices to irritate the sensitive stomach lining [9]. The present study is designed to use $A J$ extract to protect against the free radicals production and to evaluate its role against $H$. Pylori and many other bacteria species including E. coli. It is also intended to delineate the antibacterial mechanism of action of $A J$ and comparing its action with that of cefotaxime and tetracycline. The antioxidant capacity of the $A J$ was also investigated by using the trolox equivalent antioxidant capacity.

\section{Aim of the work}

- To elucidate the antibacterial action of $A J$ against $H$. pylori and different other bacterial cultures in vitro.

- To delineate the potential antibacterial mechanism of action of $A J$ in comparison with amoxicillin and clarithromycin.

- To measure the trolox equivalent antioxidant capacity (TEAC) of the $A J$ water extract in-vitro.

\section{Work Design}

- The effect of the watery extract of AJ has been tested on different bacterial colonies in cultures including the H. Pylori species.

- The effect of the watery extract of AJ versus clarithromycin and amoxicillin has been investigated against various types of bacteria in culture

- The total antioxidant capacity of the extract is measured by using the trolox equivalent antioxidant capacity technique.

\section{MATERIALS AND METHODS:}

Materials:

Artemisia judaica dried leave were purchased from a local herbal market in Riyadh city, KSA

Bacteria: Staphilococcus aureus, Ehirichia coli, Salmonella typhi, Pseudomonas aeruginosa, Streptococcus group B. and Helicobacter pylori

Various strains of bacteria were isolated \& identified in its specific cultures in vitro. This was done in the KFMC microbiology laboratories.

Antibiotics: cefotaxime and tetracycline were generously obtained KFMC hospital Pharmacy. 
Culture media like blood Agar medium, Mueller Hinton Agar \& Saborod dextrose agar were obtained fro KFMC hospital laboratories

\section{Chemicals:}

- Trolox, a water-soluble vitamin E analog.

- 2,2'-azinobis(3-ethylbenzothiazoline-6-sulfonic acid) diammonium salt (ABTS)

- Instruments:

- Spectrophotometer, (Pharmacia LKB, Ultrospec III - England)

- Rotary evaporator, Heidolph Instruments GmbH \& Co.KG Walpersdorfer Str. 12, D91126 Schwabach, Germany

- Glass tools and polyethylene tubes

\section{Methods:}

Preparation of Artemisia judaica extract:

- Hot water extraction (decoction):

- It is a usual popular preparation. it is done according to the methods described by Abdel-Salam et al. [10]: Approximately $50 \mathrm{~g}$ of Artemisia judaica material is cut into small pieces, melded and placed in a flask $(2 \mathrm{~L})$ with $1000 \mathrm{~mL}$ of distilled water and boiled for $15 \mathrm{~min}$, then the mixture is filtered twice, first through cheese-cloth (50\% cotton/50\% polyester) and then through filter paper (Whatman No. 2). The final concentrations of the preparation of Artemisia judaica is $5 \%$ as a total solids. The amount of obtained Artemisia judaica extract is preserved in sterile dark bottles (500 $\mathrm{mL})$ in a cool environment $\left(4^{\circ} \mathrm{C}\right)$ until further use. All these processes were done in the KFMC and FOM laboratories.

- Soaked preparation (infusion): Approximately $50 \mathrm{~g}$ of Artemisia judaica material is cut into small pieces, melded and placed in a flask $(2 \mathrm{~L})$ with $1000 \mathrm{~mL}$ of distilled water for over night then the mixture is filtered twice.

- Preparation of Aqueous Extract of Artemisia judaica under vacuum:

- One hundred and fifty milliliters of distilled water were added to 30 grams of the shade-dried herb, and then the mixture boiled for about 20 minutes. The whole mass was filtered and concentrated under vacuum to about $30 \mathrm{ml}$. The concentration of the dried A. judaica was $1 \mathrm{~g} / \mathrm{ml}$ in the final extract. The extract was stored in refrigerator in well-closed dark glass container.

\section{Bacteriological Study:}

\section{Culture medium used for susceptibility test:}

For Helicobacter pylori and Streptococcus group B we used Blood Agar medium.

For Escherichia coli, Staphilococcus aureus and Salmonella typhi we used Mueller Hinton Agar. For Pseudomonas aeruginosa we used saborod dextrose agar.

\section{Antibiotics used for the comparison:}

Tetracycline and Cefotaxime versus Artemisia judaica extract in three concentrations 5\%, $10 \%$ and $20 \%$.

\section{Method}


Different bacterial species where collected from the microbiology laboratory in the hospital of King Fahad Medical City in Riyadh-Kingdom of Saudi Arabia. The strains where isolated from different medical specimens by the hospital lab. and identified by morphology of the colonies and the biochemical reactions using API. The identified isolates where kept freezed in $-80{ }^{\circ} \mathrm{C}$ refrigerator in order to maintain the strain for research.

The bacterial strains where cultured on the suitable medium for the susceptibility test for each strain, and then a pharmaceutical disk saturated with the selected antibiotic under investigation is placed on the surface of the medium inoculated on the whole surface with the test organism.

$5,10 \& 20 \%$ of Artemisia judaica extract were prepared by the above mentioned two different methods. Then a disk of sterile filter paper is saturated with the different concentrations of the filtrate of the plant extract and placed on the surface of the agar medium which has been inoculated earlier with the organism under investigation.

The diameters of the circular "halo" (technically known as a "plaque," or zone of inhibition) surrounding the disks of antibiotics or the plant extracts are measured for comparison of the sensitivity of different bacterial species to the agents used.

\section{Biochemical study:}

\section{Measurement of antioxidant capacity:}

- TEAC (Trolox equivalent antioxidant capacity) assay. The method is based on the ability of antioxidant molecules to quench the long-lived ABTS + + , a blue-green chromophore with characteristic absorption at $734 \mathrm{~nm}$, compared with that of Trolox, a water-soluble vitamin $\mathrm{E}$ analog. The addition of antioxidants to the preformed radical cation reduces it to ABTS, determining a decolorization. A stable stock solution of ABTS + is produced by reacting a $7 \mathrm{mmol} / \mathrm{L}$ aqueous solution of ABTS with $2.45 \mathrm{mmol} / \mathrm{L}$ potassium persulfate (final concentration) and allowing the mixture to stand in the dark at room temperature for $12-16 \mathrm{~h}$ before use [11]. At the beginning of the analysis day, an ABTS + + working solution is obtained by the dilution in ethanol of the stock solution to an absorbance of $0.70 \pm 0.02 \mathrm{AU}$ at $734 \mathrm{~nm}$, verified by a Hewlett-Packard 8453 Diode Array spectrophotometer (HP, Waldbronn, Germany), and used as mobile phase in a flow-injection system, according to Pellegrini et al [12]. Results are expressed as TEAC in mmol of Trolox per L (water extract) of sample. All these processes were done in the FOM, KFMC laboratories.

\section{Statistical analysis:}

- Data were analyzed by using the Student t- test described by Sendecor and Cochran (1969). p value $<0.05$ was considered significant.

\section{RESULTS:}

\section{Bacteriological Results:}

The sensitivity of the Helicobacter pylori and different other bacterial species were tested against 5\%, $10 \% \& 20 \%$ of Artemisia judaica extracts and compared with two antibiotics of known mechanism of actions cefotaxime, inhibits cell wall synthesis, and tetracycline which inhibits bacterial protein synthesis. Unfortunately we did not find any effect for Artemisia judaica extract prepared by the above mentioned two methods of preparations and even in 
high enough $20 \%$ concentrations on the growth of any of the used strains of bacteria in different culture media compared with cefotaxime and tetracycline

Tab. (1) and Fig. (1)

Table 1. Effects of cefotaxime, tetracycline versus Artemisia judaica against different bacterial species

\begin{tabular}{l|ccc}
\hline \multicolumn{1}{l|}{ Agent } & Cefotaxime & Tetracycline & Artemisia judaica 5-20 \% \\
\cline { 1 - 1 } Organism & & & \\
Staphilococcus aureus & $37 \mathrm{~mm}$ & $30 \mathrm{~mm}$ & $0 \mathrm{~mm}$ \\
Ehirichia coli & $30 \mathrm{~mm}$ & $22 \mathrm{~mm}$ & $0 \mathrm{~mm}$ \\
Salmonella typhi & $29 \mathrm{~mm}$ & $0 \mathrm{~mm}$ & $0 \mathrm{~mm}$ \\
Pseudomonas aeruginosa & $14 \mathrm{~mm}$ & $12 \mathrm{~mm}$ & $0 \mathrm{~mm}$ \\
Streptococcus group B & $43 \mathrm{~mm}$ & $32 \mathrm{~mm}$ & $0 \mathrm{~mm}$ \\
Helicobacter pylori & $83 \mathrm{~mm}$ & $83 \mathrm{~mm}$ & $0 \mathrm{~mm}$ \\
\hline
\end{tabular}

Diameters $(\mathbf{m m})$ of area affected in culture

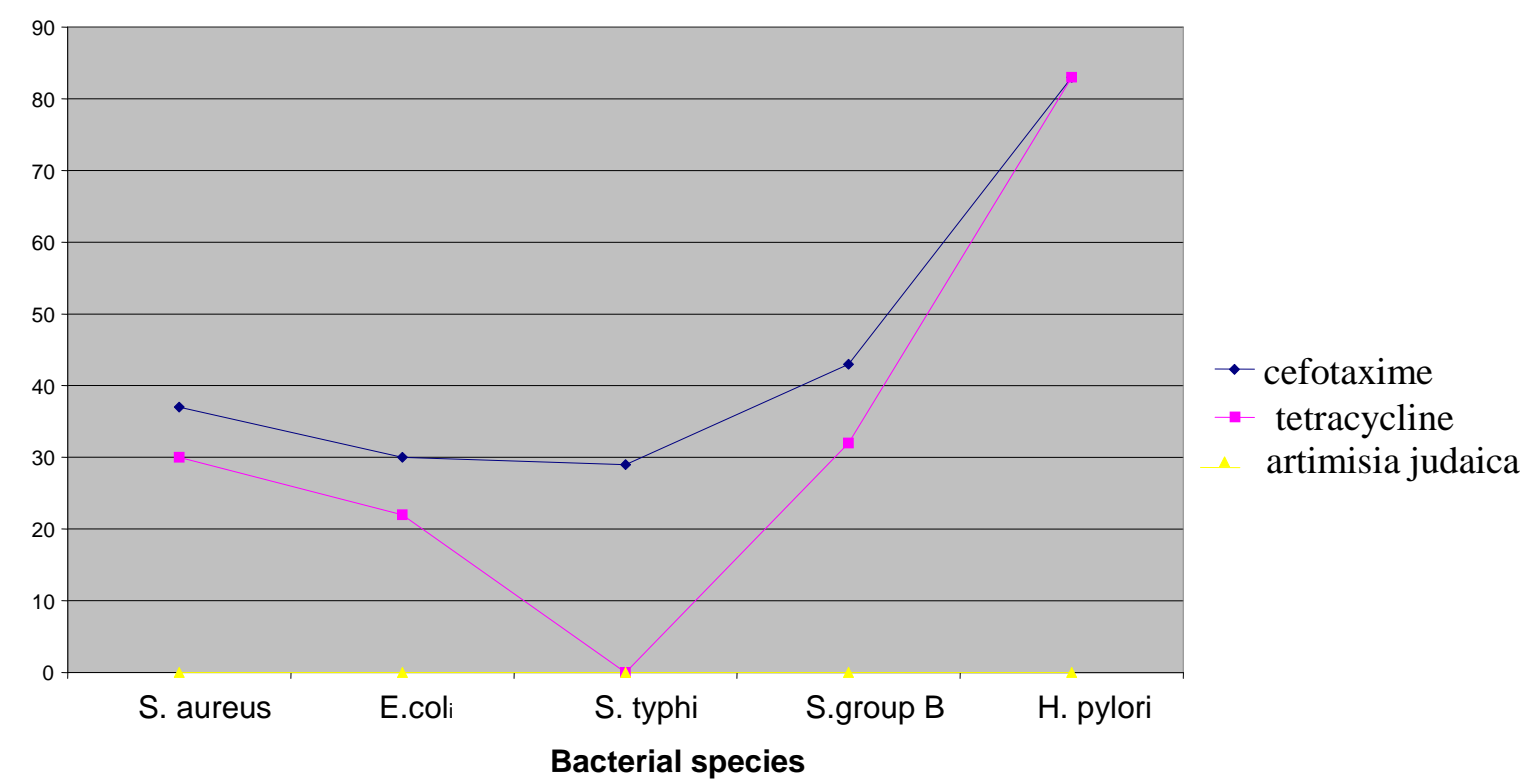

Figure 1: Sensitivity of bacteria strains to Artemisia Judaica versus Antibiotics

\section{Biochemistry Results:}

By using trolox standard antioxidant curve Fig (2) as a reference to the antioxidant capacity of the $A J$ extract preparations, it was found that all types of preparations produced a significant TEAC $(\mathrm{p}<0.005)$ compared with blank. in this regard also the concentrated vacuum extract produced a significant $(\mathrm{p}<0.05)$ antioxidant effect compared with decoction (tea) and soaked (infusion) preparations Tab. (2) Fig. (3)

Table 2. The trolox equivalent antioxidant capacity of AJ preparations

\begin{tabular}{lccc|c}
\hline & $\boldsymbol{1}^{\text {st }}$ set & $\mathbf{2}^{\text {nd }}$ set & $\boldsymbol{3}^{\text {rd }}$ set & Mean \pm SD \\
\hline Vacuum ext. & 0.447 & 0.392 & 0.399 & $0.413 \pm 0.030^{*}$ \\
Tea & 0.287 & 0.308 & 0.313 & $0.303 \pm 0.0137$ \\
Soaked & 0.232 & 0.290 & 0.251 & $0.258 \pm 0.029$ \\
\hline
\end{tabular}

$\mathrm{P}<0.005$ 


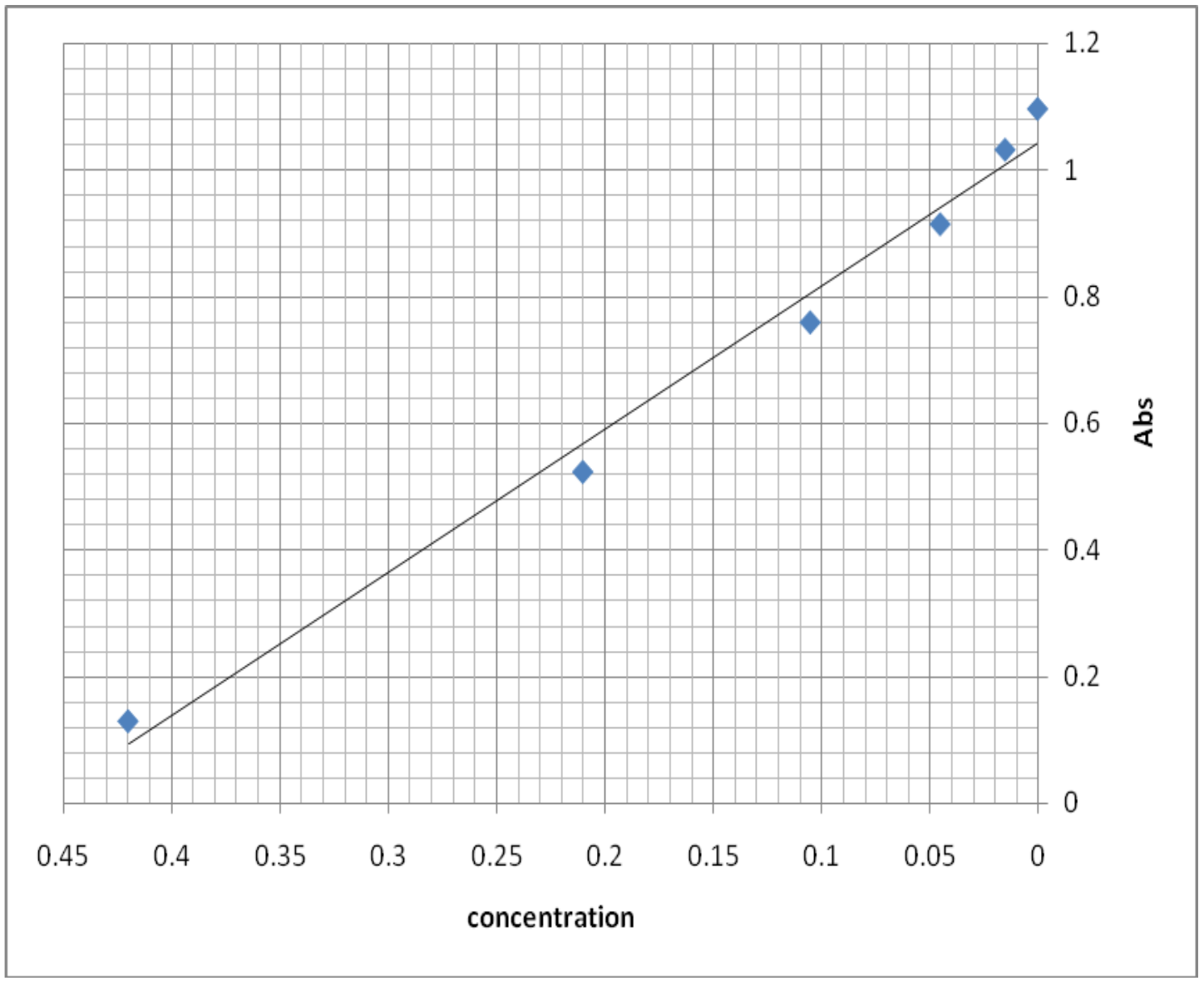

Figure 2: Trolox standard antioxidant capacity curve; it is noticed that as the trolox increased more of the ABTS is scavenged and subsequently the absorbance decreased

TEAC

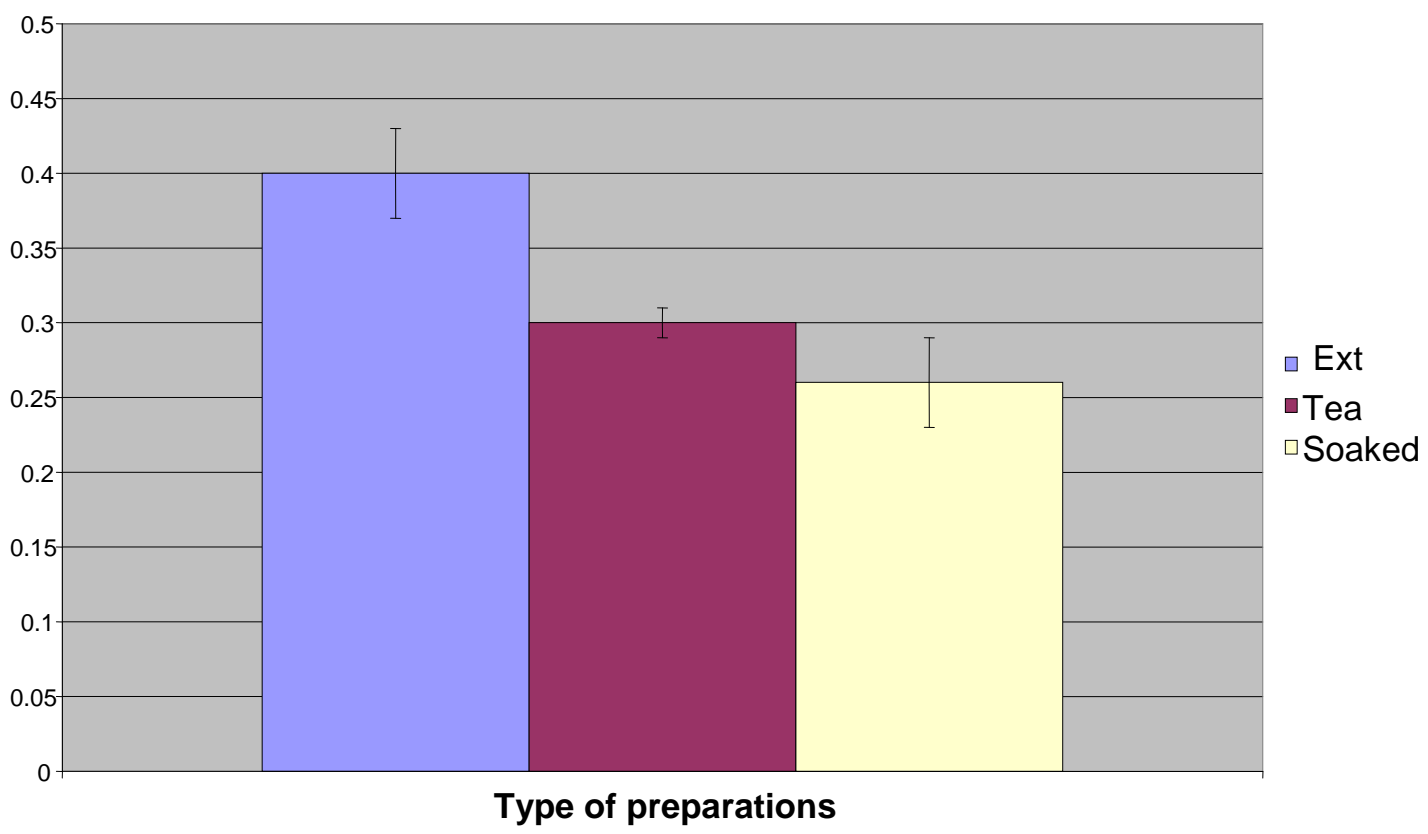

Figure 3: Antioxidant effect of three preparations of Artemisia Judaica 


\section{DISCUSSION:}

Artemisia judaica is one of the common species of the genus Artemisia that grows in Middle East deserts where animals graze on it. It is widely used in folk medicine and is recommended as a healer plant in traditional medicine by Bedouins in Saudi Arabia desert and Sinai, Egypt. The volatile oil prepared from the flowering branches of Artemisia judaica has anthelmintic, antiinflammatory, analgesic and antipyretic effects; in addition to antimicrobial activity against Staphylococcus aureus, Candida albicans and Rodotorula ruba [13].

Aqueous extract of the ground aerial parts of Artemisia arborescens induced a concentration dependent reduction in the amplitude of the phasic contractions and tone of the rat ileum [14]. The flavone isolated from A. judaica (cirsimaitin), has the same effect [1]. The aqueous extract of A. herba-alba produced initial hyperglycaemia which was followed by hypoglycaemia in normal and alloxan -treated rabbits and mice [15].

Methanol extract of Artemisia pallens induced significant blood glucose lowering effect [16]. Artemisinin (a compound isolated from Artemisia annua), is a potent cancer chemoprevention agent [17].

Phytochemical analysis of Artemisia judaica shows that it is a rich source of flavonoids including apigenin, cirsimaritin, and various novel compounds [3, 4, and 5]

The present study was designed to elucidate the antibacterial action of $A J$ against $H$. pylori and different other bacterial species, to delineate the potential antibacterial mechanism of action of $A J$ in comparison with tetracycline and cefotaxime and to measure the trolox equivalent antioxidant capacity (TEAC) of the AJ water extract.

In our present study we used the boiled or soaked water crude extract of the dried leaves of Artemisia judaica plant as usually prepared by people of our Arabian area and also we get concentrated preparation under vacuum.

Investigation of the crude extract on bacterial sensitivity in culture and the trolox equivalent antioxidant capacity (TEAC) were run to evaluate the beneficial effects of this plant.

Unfortunately, in our study we have not found any antibacterial effect for the crude extract of Artemisia judaica in contrast to the results previously obtained by Charchari et al. 1996 and Batanouny et al. 1999 [13, 18] and this is may be due to different methods of extract preparations or because those authors used a single component of the crude extract after HPLC separation, or it may be also due to different plant species and culture as they used plant grown in Algeria desert while in our study we used the dried leaves of Artemisia Judaica plant grown in Saudi Arabia desert.

Because many synthetic antioxidants (butylated hydroxyanisole and butylated hydroxytoluene) have been proved to have undesirable side effects [19]. There has been an increasing interest in the use of medicinal plants rich in antioxidants to reduce free radicalsinduced tissue injury [20]. Phyto chemicals content in plants are promising alternatives to synthetic drugs.

Our present study revealed a significant $(\mathrm{p}<0.005)$ TEAC for AJ extract preparations, the results which run in parallel with that obtained by liu et al. [6]. The antioxidant effects of AJ extract open several therapeutic utilities to the plant in senility, Parkinsonism, NSAIDinduced peptic ulcers and many other disorders induced by free radicals generation. This study needs more investigations and extensions to evaluate the AJ extracts in the above mentioned disorders. 


\section{CONCLUSION:}

Our study demonstrated that $(\mathrm{AJ})$ water extracts prepared by any of the above mentioned methods has a considerable antioxidant capacity. However, these extracts have no antibacterial effects neither against $\mathrm{H}$. pylori or any other bacterial specie

\section{Competing Interests:}

The authors have no financial interests or conflicts of interest .

\section{Authors' Contributions:}

All authors contributed to this study .

\section{Acknowledgements and Funding :}

The authors would like to thank King Fahad Medical City - Faculty of Medicine for their financial support.

\section{REFERENCES:}

1. Abdalla SS, Abu-Zagra MH. Effects of cirsimaritin, a flavone isolated from Artemisia judaica, on isolate guinea-pig ileum. Planta Med 1987; 53: 322-324.

2. Khafagy SM, El-Din AA, Jakupovic J, Zdero C, Bohlmann F. Glaucolide-like sesquiterpene lactones from Artemisia judaica. Phytochemistry 1988; 27: 1125-1128.

3. Khafagy SM, Tosson S. Crystallographic optical and chromatograph studies of judaicin bitter, principle of Artemisia judaica L. Planta Med 1968; 16: 446-449.

4. Saleh MA. Volatile components of Artemisia monosperma and Artemisia judaica L. growing in the Egyptian deserts. Biochem Syst Eco1985; 13: 265-269.

5. Saleh MA, El-Ghazooly SI, Abou-Zaid MM. Flavonoid of Artemisia judaica, A. monosperma and A. herba-alba. Phytochemistry 1987; 26: 3059-3064.

6. Liu CZ, Murchb SJ, EL-Demerdash M, Saxena PK. Artemisia judaica L.: micropropagation and antioxidant activity. Journal of Biotechnology 2004; 110: 6371

7. Nofal MS, Mahmoud SS, Ramadan A, Soliman S, Fawzy R. Anti-Diabetic Effect of Artemisia judaica Extracts. Research Journal of Medicine and Medical Sciences 2009; 4(1): 42-48.

8. El-Sayed MA, Tawfek S, Abdel Aziz S. The protective effects of some antioxidants against experimentally-induced gastric ulcers in rats. ZUMJ 1998; 6: 17-29.

9. Chey WD, Wong BC. American College of Gastroenterology guideline on the management of Helicobacter pylori infection. Am J Gastroenterol 2007; 102(8):18081825.

10. Abdel-Salam AM, Ammar AS, Galal WK. Evaluation and properties of formulated low calories functional yoghurt cake. J Food Agric Environ 2009; 7: 212-218.

11. Pellegrini N, Re R, Yang M, Rice-Evans CA. Screening of dietary carotenoids and carotenoid-rich fruit extracts for antioxidant activities applying the 2, 2'-azobis(3ethylenebenzothiazoline-6-sulfonic) acid radical cation decolorization assay. Methods Enzymol 1999. 299:379-389. 
12. Pellegrini N, Del Rio D, Colombi B, Bianchi M, Brighenti F. Application of the 2, 2'azobis(3-ethylenebenzothiazoline-6-sulfonic acid) radical cation assay to a flow injection system for the evaluation of antioxidant activity of some pure compounds and beverages. J Agric Food Chem 2003; 51:260-264. .

13. Batanouny KH, Abou Tabl S, Shabana M, Soliman F. Wild medicinal plants in Egypt:

14. An Inventory to Support Conservation and Sustainable Use. Chaper 2: Pharmacopoeial Wild

15. Medicinal Plants in Egypt Academy of Scientific Research and Technology, Egypt International

16. Union for Conservation (IUCN) 1999; 117-119.

17. Abu Zarga M, Qauasmeh S, Munsoor SM, Abdalla S. Chemical constituents of Artemisia arborescens and the effect of the aqueous extract on rat isolated smooth muscle. Planta Medica 1995; 61: 242-245.

18. Marrif HI, Ali BH, Hassan KM. Some pharmacological studies on Artemisia herbaalba (Asso.) in rabbits and mice. Journal of Ethnopharmacology1995; 49: 5155.

19. Subramoniam A, Pushpangadan P, Rajasekharan S, Evans DA, Latha PG, Valsaraj R. Effects of Artemisia pallens Wall. On blood glucose levels in normal and alloxanInduced diabetic rats. Journal of Ethnopharmacology 1996; 50: 13-17.

20. Lai H, Singh NP. Oral artemisinin prevents and delays the development of 7, 12dimethylbenz[a] anthracene (DMBA) -induced breast cancer in the rat. Cancer Lett 2006; 231: 43-48.

21. Charchari S, Dahoun A, Bachi F, Benslimani A. In vitro antimicrobial activity of essential oils of artimicia herba- beta and artemicia judaica from Algeria. Rivista Italiana 1996; 18: 3-6

22. Jayaprakasha GK, Mandadi KK, Poulose SM, Jadegoud Y, Nagana-Gowda GA, Patil BS. Inhibition of colon cancer cell growth and antioxidant activity of bioactive compounds from Poncirus trifoliata (L.) Raf Bioorg Med Chem 2007; 15: 4923-4932.

23. Zhishen J, Mengcheng T, Jianming W. The determination of flavonoid contents in mulberry and their scavenging effects on superoxide radicals. Food Chem 1999; 64: 555-559. 